\title{
Gluten, Dysbiosis, and Genetics in Celiac Disease: All Are Important
}

\author{
Ewa Waszczuk ${ }^{1}$ - Karolina Waszczuk ${ }^{2}$
}

Received: 26 May 2016/ Accepted: 21 July 2016/Published online: 1 August 2016

(c) The Author(s) 2016. This article is published with open access at Springerlink.com

To the Editor,

We have read with a great interest the article "Gut microbiota and celiac disease" by Marasco et al. which provides the latest advances in understanding the role of the dysbiosis in the pathogenesis of celiac disease (CD) and the influence of a gluten-free diet (GFD) on gut microbiota.

However, we disagree with their statement that the period of gluten introduction into the infant diet increases the prevalence of $\mathrm{CD}$. It is against the current knowledge, especially regarding healthy children, without increased risk of CD. Recent studies (CELIPREV and Prevent CD) have shown that early (at 4 or 6 months of age) exposition to gluten does not influence the absolute risk of CD during the childhood [1, 2]. Furthermore, the European Society for Paediatric Gastroenterology, Hepatology and Nutrition (ESPHAGAN) has changed previous recommendations and now gluten may be introduced into the infant diet from 4 to 12 months completed [3]. Of particular concern are children who have a first-degree relative with $\mathrm{CD}$, because they have a $10-15 \%$ of risk to be homozygous for HLA-DQ2.

Ewa Waszczuk

ewawaszcz@interia.pl

Karolina Waszczuk

Karolina.waszcz@gmail.com

1 Department of Gastroenterology and Hepatology, Wroclaw Medical University, Borowska 213, 50-556 Wrocław, Poland

2 Department of Pediatrics and Infectious Diseases, Wroclaw Medical University, T.Chalubinskiego 2-2a, 50-368 Wrocław, Poland
In this case, early gluten exposition may provoke an immunologic response. It is still under debate if it is beneficial for them to delay the gluten exposure, but the data are conflicting and timing of gluten introduction seems to play a minor role in onset of symptoms.

It was a great value of the Marasco et al.'s paper to mention the impact of environmental conditions influencing a microbiota composition, i.e., the mode of delivery, breastfeeding, early infections, and antibiotic use. We would like to emphasize that also other drugs, such as PPI or NSAIDs (both commonly overused), change the balance between bacteria and may cause dysbiosis [4, 5]. Every physician should be aware of the complex impact of prescribed therapy, especially in a patient with a chronic condition like CD.

Gut microbiota fluctuates over the first 2-3 years of life, in young group of patients there is a high interindividual variability, and the outcomes may vary depending on different environmental factors. In studies from Collado et al. and Sanz et al. cited by Marasco the mean age of participants was 2.2 and 3 years of age, respectively, so the drawn conclusions may not be repetitive and the issue should be investigated in further studies.

Generally, we support the statement that on GFD there is no complete restoration of gut microbiota. However, in contrary to the authors, we can conclude that on GFD often remains unbalanced microbial composition with predominance of potential harmful bacteria species, i.e., increase in Enterobacteriaceae and Staphylococcus spp. and decreased levels of Lactobacillus and Bifidobacterium [6, 7]. In consequence, patients may suffer from persisting gastrointestinal symptoms despite the GFD.

Finally, we would like to correct that Staphylococcus spp. neither are Gram (-) bacteria nor belong to Proteobacteria. 


\section{Compliance with ethical standards}

Conflict of interest The authors declare that they have no conflict of interest.

Open Access This article is distributed under the terms of the Creative Commons Attribution-NonCommercial 4.0 International License (http://creativecommons.org/licenses/by-nc/4.0/), which permits any noncommercial use, distribution, and reproduction in any medium, provided you give appropriate credit to the original author(s) and the source, provide a link to the Creative Commons license, and indicate if changes were made.

\section{References}

1. Lionetti E, Castellaneta S, Francavilla R, et al. Introduction of gluten, HLA status, and the risk of celiac disease in children. $N$ Engl J Med. 2014;371:1295-1303.
2. Vriezinga SL, Auricchio R, Bravi E, et al. Randomized feeding intervention in infants at high risk for celiac disease. $N$ Engl J Med. 2014;371:1304-1315.

3. Szajewska H, Shamir R, Mearin L, et al. Gluten Introduction and the Risk of Coeliac Disease: a Position Paper by the European Society for Pediatric Gastroenterology, Hepatology, and Nutrition. J Pediatr Gastroenterol Nutr. 2016;62:507-513.

4. Jackson MA, Goodrich JK, Maxan ME, et al. Proton pump inhibitors alter the composition of the gut microbiota. Gut. 2016;65:749-756.

5. Rogers MA, Aronoff DM. The influence of non-steroidal antiinflammatory drugs on the gut microbiome. Clin Microbiol Infect. 2016;22:178.e1-178.e9.

6. Di Cagno R, De Angelis M, De Pasquale I, et al. Duodenal and faecal microbiota of celiac children: molecular, phenotype and metabolome characterization. BMC Microbiol. 2011;11:219.

7. De Palma G, Nadal I, Collado MC, et al. Effects of a gluten-free diet on gut microbiota and immune function in healthy adult human subjects. Br J Nutr. 2009;102:1154-1160. 